\title{
Parameters of two-dimensional perineal ultrasonography for evaluation of urinary incontinence after Radical Prostatectomy
}

Danilo Souza Lima da Costa Cruz¹, Carlos Arturo Levi D’Ancona², Jamal Baracat², Marco Antonio Dionisio Alves ${ }^{1}$, Marcelo Cartapatti², Ronaldo Damião ${ }^{1}$

${ }^{1}$ Hospital Universitário Pedro Ernesto - State University of Rio de Janeiro, Rio de Janeiro, RJ, Brazil; ${ }^{2}$ Hospital de Clinicas - State University of Campinas, Campinas, São Paulo, SP, Brazil

\section{ABSTRACT}

Introduction: Urinary incontinence remains a major concern for patients undergoing radical prostatectomy. Its prevalence can reach 20\% in the late postoperative period. Materials and Methods: This clinical study investigated the differences of a dynamic evaluation of the urethra and pelvic floor contraction using perineal ultrasound in men without prostate surgery and in men submitted to radical prostatectomy with and without stress urinary incontinence. Ninety two male patients were included, which 70\% of them underwent radical prostatectomy (RP) for more than one year. Thirty one men with clinically post prostatectomy incontinence were compared by two-dimensional (2D) perineal ultrasound to 34 patients without post prostatectomy incontinence and to 27 men without surgery in two centers in Brazil.

Results: Our results showed that the continent group presented the urethral angle at rest significantly lower than the prostate group $(p=0.0002)$. We also observed that the incontinent group showed the displacement of the anterior bladder neck during contraction significantly lower than the continent group ( $p=0.008)$.

Conclusions: We found that the continent group presented the urethral angle at rest significantly lower than the prostate group. The incontinent group also showed the anterior bladder neck displacement during contraction significantly lower than the continent group. It was more evident when the severe incontinent group and the continent group were compared.

\section{ARTICLE INFO}

\section{Key words:}

Urinary Incontinence; Stress,

Perineum; Pelvic Floor;

Prostatectomy

Int Braz J Urol. 2014; 40: 596-604

Submitted for publication:

April 09, 2014

Accepted after revision:

July 04, 2014

\section{INTRODUCTION}

Treatment of localized prostate cancer by radical prostatectomy or radiotherapy can be curative. The removal of the prostate and surrounding tissues can lead to urinary incontinence. Even in recent series, its prevalence varies from $6 \%$ to $20 \%(1-3)$. There are few long term complications which are as inconvenient or annoying as urinary incontinence. In addition to the adverse impact on the social life of affected patients, there are also the economic consequences of urinary incontinence for these individuals and for public and private health care systems (4).

Because of its high prevalence after radical prostatectomy, understanding the pathophysiology of urinary incontinence has become the focus and aim of many studies (5-7). In this pursuit, functional imaging has emerged as an important instrument in the search for pre- and post-operative anatomical and physiological differences, which might help 
reduce treatment failure and suggest which treatment method is most appropriate for each patient.

Ultrasound has become an important procedure in the diagnostic evaluation of female urinary incontinence and functional disorders of the pelvic floor, replacing radiation based procedures. Hypermobility of the proximal urethra is related to the functional integrity of structures surrounding the proximal urethra. The demonstration of the mobility of the proximal urethra is thus one of the most important considerations in the evaluation of female urinary incontinence (8).

Beyond the physical examination and functional testing such as urodynamics, perineal ultrasound is considered an important tool in the diagnosis of female urinary incontinence, since it is noninvasive, avoids ionizing radiation, is well tolerated and provides useful information about the anatomical structures involved in this condition as well as surrounding pelvic organs (8).

Perineal ultrasound can also be used as a visual aid for biofeedback and as treatment control. However, this imaging method gives incomplete representation of the entire bladder and a less than ideal assessment of bladder neck funneling (8).

The standardization of perineal ultrasound is well established in the assessment of female lower urinary tract $(8,9)$. However, only four studies using perineal ultrasound in men are encountered in the literature, and just one of them evaluated urinary incontinence following radical prostatectomy (10-13).

\section{OBJECTIVE}

Use perineal ultrasound to compare the findings of dynamic evaluations of the urethra and pelvic floor contraction in men without a history of prostate surgery with men who has undergone radical prostatectomy with and without stress urinary incontinence.

\section{MATERIALS AND METHODS}

\section{Patients}

The study received institutional review committee approval and was carried out in accor- dance with the ethical standards of each hospital's institutional committee on human experimentation. Patients were enrolled in this study after approval of local ethics committee. Informed consent was obtained from all participants.

This cross-sectional cohort study initially involved 126 male patients recruited at two research centers, of which 34 were excluded. The 92 subjects included in the analysis had a mean age of 66.4 years (range from 47 to 75), and 70\% of them has undergone open radical prostatectomy (RP) at least 12 months earlier. Thirty-one men with post-prostatectomy incontinence were compared to thirty-four patients without post prostatectomy incontinence and to twenty seven men with no prior history of prostate surgery.

Age and Body Mass Index (BMI) were recorded for all patients. Incontinent patients were stratified according to the degree of incontinence as measured using the $24 \mathrm{~h}$ Pad test: light: 0-100g; moderate: $100-400 \mathrm{~g}$; severe $>400 \mathrm{~g})(16,17)$. Urinary tract infections were ruled out by urine culture in all subjects prior to the ultrasound examination. Urodynamics testing and the $24 \mathrm{~h}$ Pad test were performed in all subjects in the incontinent group prior to the ultrasound examination.

Exclusion criteria included prior pelvic radiotherapy, low bladder compliance, urethral stricture, significant neurological disease or poorly controlled diabetes, presence of active infection, pelvic trauma with urethral injury, previous surgery for the treatment of sphincter urinary incontinence, and bladder overactivity unresponsive to medical management.

\section{Methods}

Ultrasonography images were obtained and assessed by a single examiner at both teaching hospitals. A SONACE 8000SE Medison, with an abdominal 2.0 to $5.0 \mathrm{MHz}$ convex transducer was used at the Pedro Ernesto University Hospital. A Toshiba Xario with an abdominal 3.0 to $6.0 \mathrm{MHz}$ convex transducer was used at the University of Campinas Hospital.

In a supine position, patients were investigated with their legs bent and slightly rotated outwards, similar to the lithotomy. Images were 
reproduced in a standing position only in cases where there was a failure to demonstrate funneling of the bladder neck $(8,9)$.

The transducer was placed on the perineal area in a sagittal orientation, to obtain images of the pubic symphysis, bladder, bladder neck and urethra $(13,16)$. Ultrasound assessment of the male bladder is best achieved when the urine volume is at least $300 \mathrm{~mL}$. If a subject - particularly in the incontinent group - was unable to maintain this volume, an infusion of $0.9 \%$ normal saline via Foley catheter was performed. The catheter was promptly removed before measurements were obtained $(8,16)$.

During the examination, we were able to evaluate the mobility of the proximal urethra, urethral angle, funneling of the bladder neck, and voluntary contraction of the pelvic floor, following standardized criteria under three conditions: at rest, during contraction and during a Valsalva maneuver $(8,9,13,17)$.

The extent of dilatation of the proximal urethra was gauged by measuring the funneling index during the Valsalva maneuver and at rest. The funneling index is calculated as the product of the width in millimeters of the bladder neck and the depth to the apex of urethral dilation (13, 18) (Figure-1).
The position of the bladder neck was determined at rest, during the Valsalva maneuver and during pelvic floor contraction. Measurements were made using an XY coordinate system, with the pubis as the reference point. The $\mathrm{X}$ axis was drawn by a line on the upper edge of the pubic symphysis. The $\mathrm{Y}$ axis was drawn perpendicular to the $\mathrm{X}$ axis at the upper edge of the pubic symphysis.

For exact positioning of the bladder neck, we used the most proximal urethral wall, in the immediacy of the bladder. We calculated the anterior and the posterior bladder neck mobility under conditions of rest, pelvic floor contraction and Valsalva maneuver. The movement of the bladder neck was calculated by the following formula: $\sqrt{ }(\mathrm{x} 2-\mathrm{x} 1)^{2}+(\mathrm{y} 1-\mathrm{y} 2)^{2}$, where $\mathrm{x} 1$ and $\mathrm{y} 1$ represent the rest coordinates $(8,9,16-19)$ (Figure 2$)$.

The presence of an intact prostate in control group subjects made it technically difficult to evaluate the bladder neck during the ultrasound examination. To address these challenges we added two more measurements: urethral angle and distance of the pubis. The urethral angle was defined as the angle formed by the anterior wall of the penile urethra and the anterior wall of the bulbar urethra, and was measured at rest, during Valsalva, and maximum contraction (Figure-3).

Figure 1 - Funneling index during a Valsalva maneuver and at rest. This index is calculated as the product of the width in millimeters of the bladder neck and the depth to the apex of urethral dilatation.

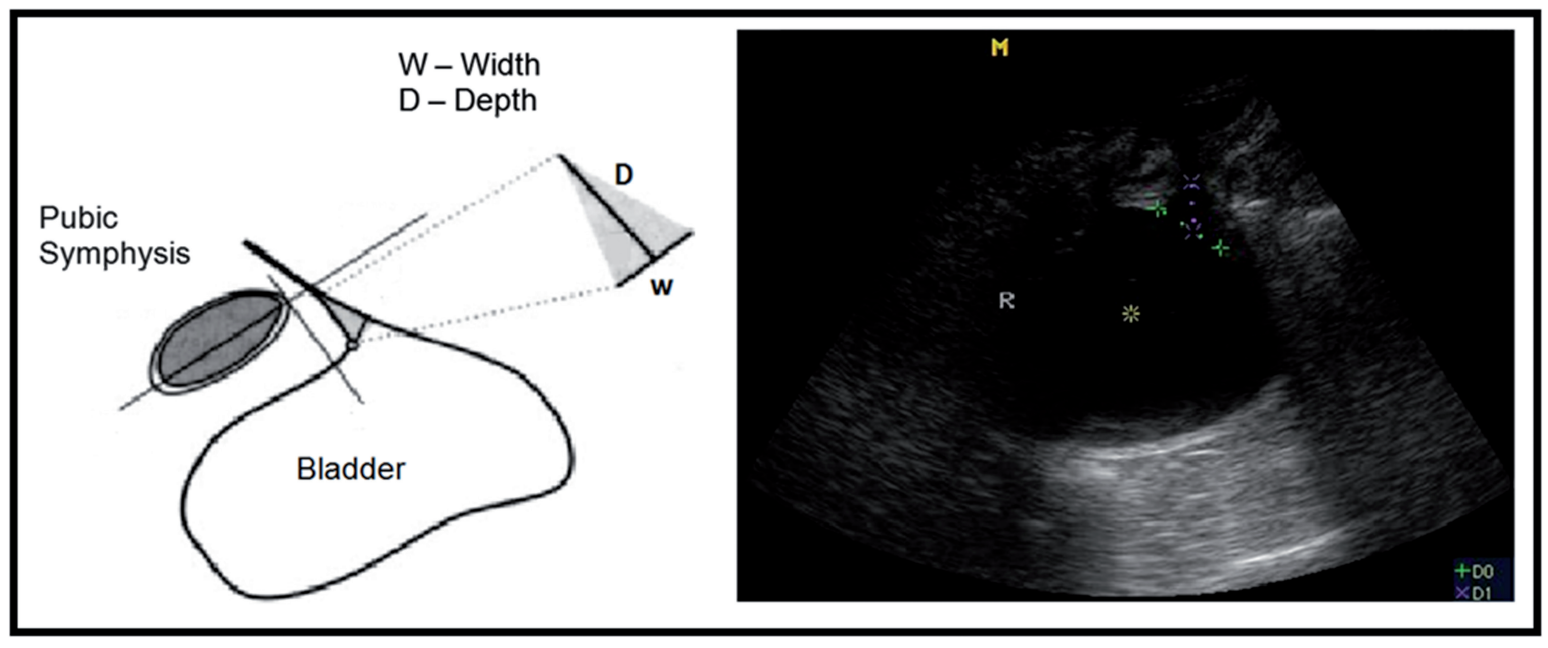


Figure 2 - Position of anterior bladder neck using an $X Y$ coordinates system during contraction. The $X$ axis was drawn by a line on the upper edge of the pubic symphysis. The $Y$ axis was drawn perpendicular to the $X$ axis at the upper edge of the pubic symphysis.

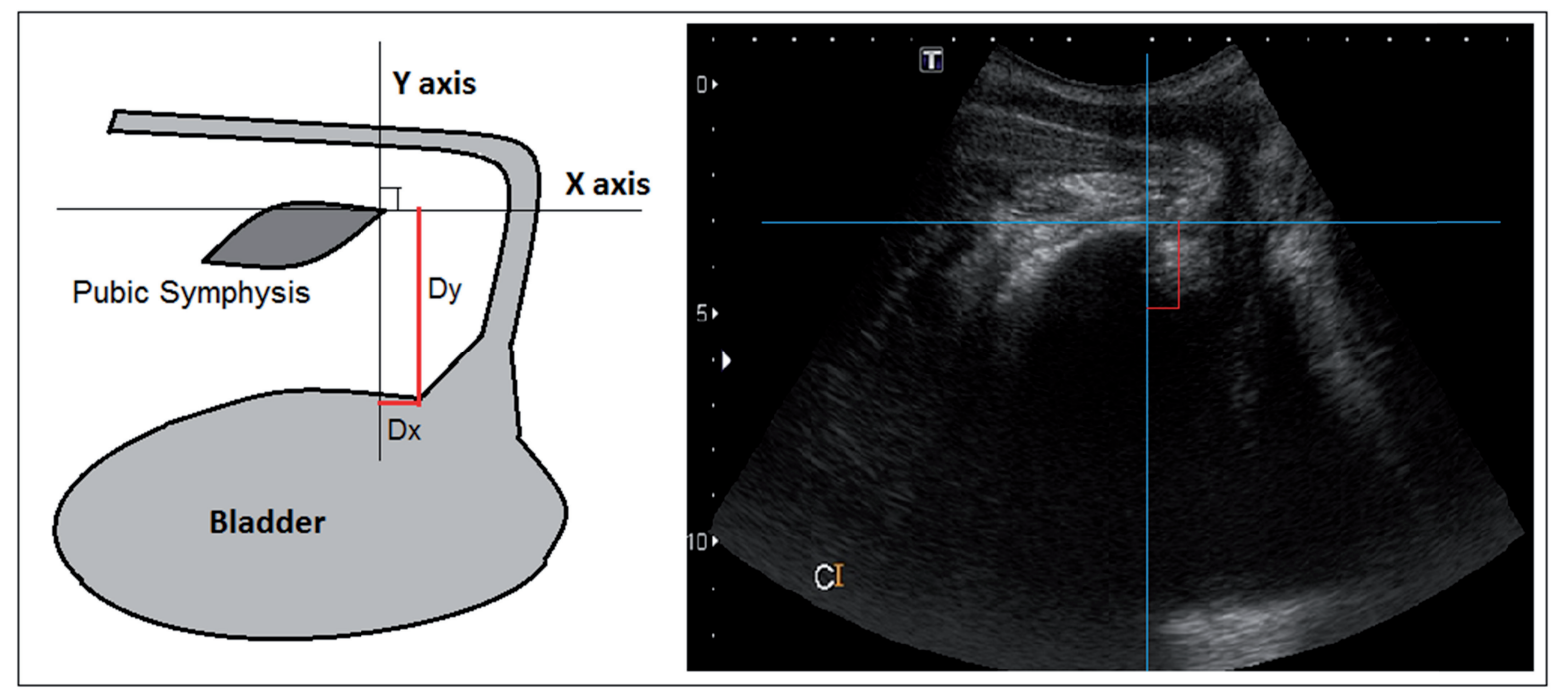

Figure 3 - Urethral angle in a patient with a prostate. The angle formed by the anterior wall of the penile urethra and the anterior wall of the bulbar urethra measured at rest, during Valsalva, and during contraction.

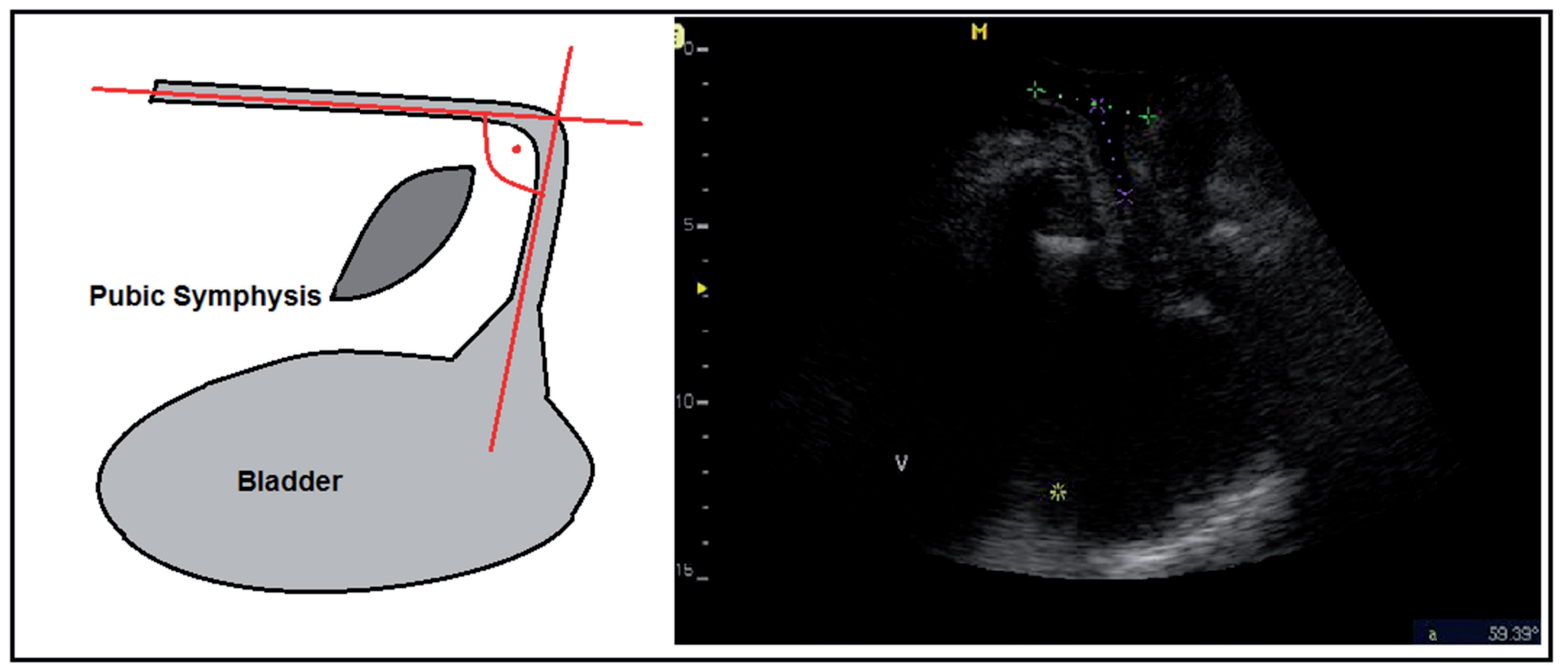

The pubis distance was defined as the distance between the pubis and the anterior wall of the bulbar urethra through an imaginary line which bisects the pubic symphysis (Figure 4).

Normal contraction was confirmed by correct cranioventral displacement of pelvic structures. During the ultrasound examination, all patients were asked to perform three voluntary maximal contraction efforts of the pelvic floor muscles for ten seconds and then relax. The greatest displacement was used as the basis for calculating the previously described measures (20). The data were analyzed using one-way ANOVA or Kruskal-Wallis ANOVA with statistical significance defined at the $5 \%$ level $(\mathrm{p}<0.05)$. 
Figure 4 - Pubis distance in a patient with prostate during contraction. The distance between the pubis and the anterior wall of the bulbar urethra through an imaginary line which bisects the pubic symphysis.

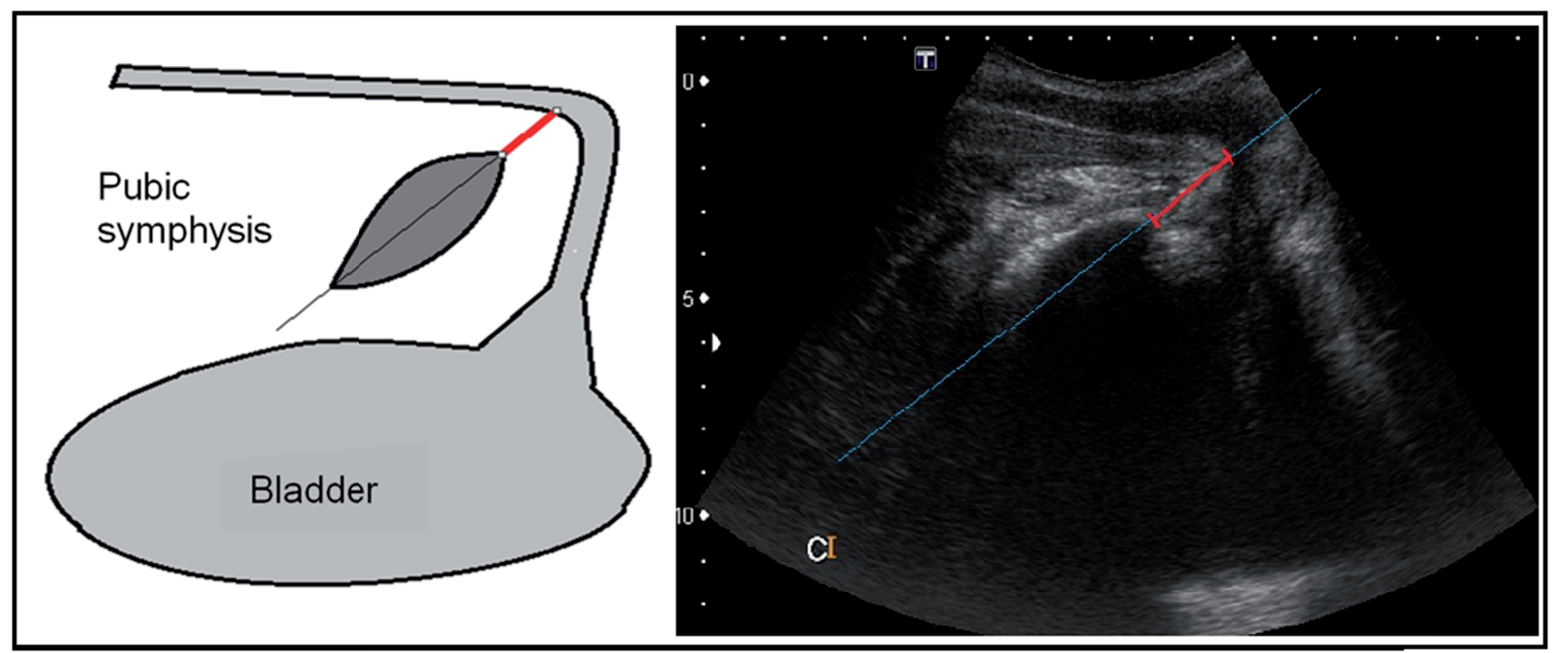

\section{RESULTS}

Table-1 provides the mean, standard deviation (SD) and median baseline values for each variable by group (non-surgery, continent and incontinent) and the corresponding descriptive level (p value) of the one-way ANOVA (age, BMI, urethral angle and distance from pubis) or Kruskal-Wallis ANOVA. Dunnett's (parametric) multiple comparison test was used to identify which group (continent or incontinent) differed significantly from the non-surgery group. Employing Dunnett's test, the continent group had a urethral angle that was significantly smaller than the non-surgery group at rest. Employing the one-way ANOVA, there was a statistically significant difference in the urethral angle at rest across groups $(p=0.0002)$.

With Kruskal-Wallis ANOVA, there was no significant difference of the urethral angle and distance of the pubis across the three groups during contraction or with Valsalva in relation to "at rest".

Table-2 provides the mean, standard error (SE) and median variations of anatomical parameters in relation to "at rest" according to group

Table 1 - Initial variables by group.

\begin{tabular}{|c|c|c|c|c|c|c|c|c|c|c|c|c|c|}
\hline \multirow{2}{*}{$\begin{array}{l}\text { Inicial } \\
\text { Variables }\end{array}$} & \multicolumn{4}{|c|}{ Non surgery $(n=27)$} & \multicolumn{4}{|c|}{ Continent $(n=34)$} & \multicolumn{4}{|c|}{ Incontinent $(n=31)$} & \multirow[t]{2}{*}{$p$ value ${ }^{a}$} \\
\hline & mean & \pm & SD & med & mean & \pm & SD & med & mean & \pm & SD & med & \\
\hline $\mathrm{BMI}\left(\mathrm{Kg} / \mathrm{m}^{2}\right)$ & 26.6 & \pm & 4.0 & 27.2 & 27.4 & \pm & 4.3 & 26.4 & 26.4 & \pm & 3.6 & 25.7 & 0.53 \\
\hline Age (years) & 65.5 & \pm & 6.8 & 67 & 65.7 & \pm & 6.5 & 67 & 68.0 & \pm & 5.6 & 69 & 0.25 \\
\hline $\begin{array}{l}\text { Urethral } \\
\text { angle at rest }\end{array}$ & 115.3 & \pm & 9.6 & 117 & 100.3 & \pm & 15.1 & 102 & 107.3 & \pm & 14.7 & 109 & $0.0002^{b}$ \\
\hline $\begin{array}{l}\text { Distance } \\
\text { from pubis at } \\
\text { rest }\end{array}$ & 1.47 & \pm & 0.39 & 1.55 & 1.59 & \pm & 0.40 & 1.53 & 1.66 & \pm & 0.51 & 1.67 & 0.29 \\
\hline
\end{tabular}

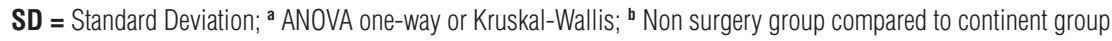


Table 2 - Variations of the anatomic position relative to "at rest" for continent and incontinent subjects.

\begin{tabular}{|c|c|c|c|c|c|c|c|c|c|}
\hline \multirow{2}{*}{ Parameters } & \multicolumn{4}{|c|}{ Continent $(n=34)$} & \multicolumn{4}{|c|}{ Incontinent $(n=31)$} & \multirow{2}{*}{$p$ value } \\
\hline & mean & \pm & SE & median & mean & \pm & SE & median & \\
\hline $\begin{array}{l}\text { Urethral angle } \\
\text { Contraction variation }\end{array}$ & -6.62 & \pm & 2.23 & -5.5 & -10.10 & \pm & 2.40 & -9 & 0.13 \\
\hline $\begin{array}{l}\text { Urethral angle } \\
\text { Valsalva variation }\end{array}$ & -3.03 & \pm & 2.40 & -1 & -3.45 & \pm & 2.89 & -2 & 0.84 \\
\hline $\begin{array}{l}\text { Funnelling area } \\
\text { Contraction variation }\end{array}$ & 0.002 & \pm & 0.122 & 0.050 & -0.252 & \pm & 0.217 & 0.070 & 0.90 \\
\hline $\begin{array}{l}\text { Funnelling area } \\
\text { Valsalva variation }\end{array}$ & 0.719 & \pm & 0.164 & 0.590 & 0.574 & \pm & 0.305 & 0.600 & 0.74 \\
\hline $\begin{array}{l}\text { Distance from pubis } \\
\text { Contraction variation }\end{array}$ & 0.103 & \pm & 0.054 & 0.130 & 0.194 & \pm & 0.045 & 0.180 & 0.34 \\
\hline $\begin{array}{l}\text { Distance from pubis } \\
\text { Valsalva variation }\end{array}$ & 0.259 & \pm & 0.064 & 0.305 & 0.280 & \pm & 0.064 & 0.25 & 0.92 \\
\hline $\begin{array}{l}\text { Anterior bladder neck } \\
\text { displacement on Contraction }\end{array}$ & 0.497 & \pm & 0.098 & 0.247 & 0.212 & \pm & 0.098 & 0.077 & 0.008 \\
\hline $\begin{array}{l}\text { Anterior bladder neck } \\
\text { displacement on Valsalva }\end{array}$ & 0.690 & \pm & 0.174 & 0.248 & 0.401 & \pm & 0.123 & 0.125 & 0.099 \\
\hline $\begin{array}{l}\text { Posterior bladder neck } \\
\text { displacement on Contraction }\end{array}$ & 1.564 & \pm & 0.455 & 0.608 & 0.691 & \pm & 0.12 & 0.485 & 0.23 \\
\hline $\begin{array}{l}\text { Posterior bladder neck } \\
\text { displacement on Valsalva }\end{array}$ & 1.365 & \pm & 0.368 & 0.538 & 0.679 & \pm & 0.12 & 0.388 & 0.82 \\
\hline
\end{tabular}

SE = Standard error; a Mann-Whitney test. Variation parameter corresponds to the difference in the position of Contraction or Valsalva in relation to rest.

(continent and incontinent) and the corresponding descriptive level ( $p$ value) of Mann-Whitney.

Anterior bladder neck displacement during contraction was significantly smaller in the incontinent group than the continent group ( $\mathrm{p}=0.008)$. There was no significant difference in other variations between the two groups.

Table-3 provides the mean, standard error (SE) and median variations of anatomical parameters in relation to "at rest" for three groups (continent, mild/moderate incontinent and severe incontinent) and the corresponding descriptive level ( $p$ value) of the Kruskal-Wallis ANOVA.
There was a statistically significant difference in anterior bladder neck displacement during contraction across groups $(\mathrm{p}=0.022)$. Using Dunnett's multiple comparison test, only the severe incontinent group showed anterior bladder neck displacement during contraction that was significantly smaller than the continent group.

\section{DISCUSSION}

Urinary incontinence remains a major concern for patients undergoing radical prostatectomy. Even in recent series, its prevalence can 
Table 3 - Variations of the anatomic position in relation to "at rest" for each group.

\begin{tabular}{|c|c|c|c|c|c|c|c|c|c|c|c|c|c|c|}
\hline \multirow{2}{*}{ Parameter } & & \multicolumn{4}{|c|}{ Continent $(n=34)$} & \multicolumn{4}{|c|}{ Mild/mod Incont. $(n=18)$} & \multicolumn{4}{|c|}{ Severe Incont. $(n=13)$} & \multirow{2}{*}{$p$ value ${ }^{a}$} \\
\hline & & mean & \pm & SE & med & mean & \pm & SE & med & mean & \pm & SE & med & \\
\hline \multirow{2}{*}{ Urethral Angle } & $\begin{array}{l}\text { Contraction } \\
\text { variation }\end{array}$ & -6.62 & \pm & 2.23 & -5.5 & -10.22 & \pm & 2.60 & -8.5 & -9.92 & \pm & 4.61 & -11 & 0.32 \\
\hline & $\begin{array}{l}\text { Valsalva } \\
\text { variation }\end{array}$ & -3.03 & \pm & 2.40 & -1 & -3.11 & \pm & 3.77 & -2.5 & -3.92 & \pm & 4.69 & -2 & 0.91 \\
\hline \multirow{2}{*}{ Funnelling Area } & $\begin{array}{l}\text { Contraction } \\
\text { variation }\end{array}$ & 0.002 & \pm & 0.122 & 0.050 & -0.358 & \pm & 0.303 & 0.030 & -0.104 & \pm & 0.312 & 0.080 & 0.74 \\
\hline & $\begin{array}{l}\text { Valsalva } \\
\text { variation }\end{array}$ & 0.719 & \pm & 0.164 & 0.590 & 0.684 & \pm & 0.480 & 0.295 & 0.420 & \pm & 0.314 & 0.830 & 0.92 \\
\hline \multirow{2}{*}{ Distance from pubis } & $\begin{array}{l}\text { Contraction } \\
\text { variation }\end{array}$ & 0.103 & \pm & 0.054 & 0.130 & 0.157 & \pm & 0.061 & 0.140 & 0.245 & \pm & 0.066 & 0.200 & 0.45 \\
\hline & $\begin{array}{l}\text { Valsalva } \\
\text { variation }\end{array}$ & 0.259 & \pm & 0.064 & 0.305 & 0.281 & \pm & 0.076 & 0.260 & 0.280 & \pm & 0.113 & 0.240 & 0.97 \\
\hline \multirow{2}{*}{$\begin{array}{l}\text { Anterior bladder neck } \\
\text { Displacement }\end{array}$} & $\begin{array}{l}\text { Contraction } \\
\text { variation }\end{array}$ & 0.497 & \pm & 0.098 & 0.247 & 0.281 & \pm & 0.167 & 0.090 & 0.118 & \pm & 0.043 & 0.051 & 0.022 \\
\hline & $\begin{array}{l}\text { Valsalva } \\
\text { variation }\end{array}$ & 0.690 & \pm & 0.174 & 0.248 & 0.512 & \pm & 0.194 & 0.16 & 0.246 & \pm & 0.117 & 0.117 & 0.17 \\
\hline \multirow{2}{*}{$\begin{array}{l}\text { Posterior bladder neck } \\
\text { Displacement }\end{array}$} & $\begin{array}{l}\text { Contraction } \\
\text { variation }\end{array}$ & 1.564 & \pm & 0.455 & 0.608 & 0.799 & \pm & 0.18 & 0.797 & 0.542 & \pm & 0.16 & 0.35 & 0.28 \\
\hline & $\begin{array}{l}\text { Valsalva } \\
\text { variation }\end{array}$ & 1.365 & \pm & 0.368 & 0.538 & 0.686 & \pm & 0.15 & 0.447 & 0.669 & \pm & 0.22 & 0.359 & 0.97 \\
\hline
\end{tabular}

vary from $6 \%$ to $20 \%$ in the late postoperative period (1-3). This work was a cross-sectional study and one possible limitation was that patients in the non-surgery group were not similar to those that were evaluated after radical prostatectomy.

The male sling has emerged as a possible treatment for patients with urinary sphincter incontinence after prostate surgery. However, several studies have shown that patients with severe incontinence did not obtain results as satisfactory as those patients with mild to moderate incontinence (21-23). Fischer et al. observed in 62 patients, those who had a $24 \mathrm{~h}$ pad test $<423 \mathrm{~g}$ showed a success rate six times higher than those who had a test $>423 \mathrm{~g}$ (15).

In our study, we observed that the incontinent group had anterior bladder neck displacement during contraction that was significantly smaller than the continent group $(p=0.008)$. However, when we divided the incontinent group into mild/ moderate and severe incontinence subgroups, we observed that there was a statistically significant difference between them. Only the severe incontinent subgroup ( $24 \mathrm{~h}$ pad test $>400 \mathrm{~g}$ ) showed significantly less displacement of the anterior bladder neck than the continent group during contraction $(p=0.022)$. These ultrasound findings are consistent with the literature and may explain the surgical results of the study by Fischer, et al. (15).

We also observed a significant difference in the urethral angle at rest between the groups $(p=0.0002)$. We found that the continent group had a urethral angle at rest that was significantly 
smaller than the urethral angle of the non-surgery group. Perhaps this difference may be one of the key factors responsible for the success of the male sling in the treatment of male urinary incontinence.

There are no published perineal ultrasound data which establish parameters are important for evaluation of urinary incontinence after radical prostatectomy. Only four studies using perineal ultrasound in men were found in the literature, and just one of them evaluated urinary incontinence after radical prostatectomy (10-13).

Stafford et al. measured the contraction of the pelvic floor muscles, clearly defining the displacement of the urethrovesical junction, ano-rectal junction and distal urethra in healthy young men $(10,12)$. Davis et al. measured men with chronic pelvic pain syndrome and concluded that men with pain had a smaller ano-rectal angle compared to men without pain (11). Kirschner-Hermanns et al. performed a study on men after radical prostatectomy. They observed that $81 \%$ of the incontinent men had good or excellent voluntary muscle contraction compared to only 50\% of continent men (13). There are only limited data comparing anatomical and physiological changes in men before and after radical prostatectomy. Normal perineal ultrasound parameters for males are not well established; we hope the findings presented here will foment further studies.

Two-dimensional perineal ultrasound provides more detail about the pathophysiology underlying urinary incontinence after radical prostatectomy. It can also be used as a visual aid for biofeedback by teaching correct pelvic floor muscle contraction in men with stress urinary incontinence after radical prostatectomy. The diagnostic precision it affords could reduce treatment failure by predicting which treatment method should be the most suitable for each patient.

This work was a cross-sectional study; one of its strong points is that the results can be generalized to other situations and to other people (external validity). We can infer that our conclusions can be actually applied in other geographic locations, since the sample showed heterogeneity. Moreover, considering the study de- sign, observational studies may be better able to reflect outcomes obtained in everyday practice. We acknowledge that future studies should to be performed in order to obtain ultrasound measure of bladder function prior to surgery so that they can be compared with the postoperative findings.

\section{CONCLUSIONS}

Perineal ultrasound is a noninvasive procedure that can be recommended for evaluation of post-prostatectomy urinary incontinence. We found that the continent group had a smaller urethral angle at rest than the group with an intact prostate. We also observed that the incontinent group demonstrated significantly less anterior bladder neck displacement during contraction than the continent group. This was more evident when the severe incontinent group was compared with the continent group.

\section{ACKNOWLEDGMENTS}

The authors thank Rosangela Aparecida Gomes Martins for her contribution to the statistical analysis.

\section{CONFLICT OF INTEREST}

None declared.

\section{REFERENCES}

1. Steiner MS, Morton RA, Walsh PC. Impact of anatomical radical prostatectomy on urinary continence. J Urol. 1991;145:512-4; discussion 514-5.

2. Eastham JA, Kattan MW, Rogers E, Goad JR, Ohori M, Boone $T B$, et al. Risk factors for urinary incontinence after radical prostatectomy. J Urol. 1996;156:1707-13.

3. Majoros A, Bach D, Keszthelyi A, Hamvas A, Mayer P, Riesz $P$, et al. Analysis of risk factors for urinary incontinence after radical prostatectomy. Urol Int. 2007;78:202-7.

4. Schiavini JL, Damião R, de Resende Júnior JA, Dornas MC, Cruz Lima da Costa DS, Barros CB. Treatment of post-prostate surgery urinary incontinence with the periurethral constrictor: a retrospective analysis. Urology. 2010;75:1488-92.

5. Bauer RM, Bastian PJ, Gozzi C, Stief CG. Postprostatectomy incontinence: all about diagnosis and management. Eur Urol. 2009;55:322-33. 
6. Rocco F, Carmignani L, Acquati P, Gadda F, Dell'Orto P, Rocco B, et al. Early continence recovery after open radical prostatectomy with restoration of the posterior aspect of the rhabdosphincter. Eur Urol. 2007;52:376-83.

7. Philippe Paparel, Oguz Akin, Jaspreet S. Sandhu, Javier Romero Otero et al. Recovery of urinary continence after radical prostatectomy: Association with urethral length and urethral fibrosis measured by preoperative and postoperative endorectal magnetic resonance imaging. European Urology. 2009; 55:629-39.

8. Dalpiaz 0, Curti P. Role of perineal ultrasound in the evaluation of urinary stress incontinence and pelvic organ prolapse: a systematic review. Neurourol Urodyn. 2006;25:301-6; discussion 307.

9. Tunn R, Schaer G, Peschers U, Bader W, Gauruder A, Hanzal $E$, et al. Updated recommendations on ultrasonography in urogynecology. Int Urogynecol J Pelvic Floor Dysfunct. 2005;16:236-41.

10. Stafford RE, Ashton-Miller JA, Constantinou CE, Hodges PW. Novel insight into the dynamics of male pelvic floor contractions through transperineal ultrasound imaging. J Urol. 2012;188:1224-30.

11. Davis SN, Morin M, Binik YM, Khalife S, Carrier S. Use of pelvic floor ultrasound to assess pelvic floor muscle function in Urological Chronic Pelvic Pain Syndrome in men. J Sex Med. 2011;8:3173-80.

12. Stafford RE, Ashton-Miller JA, Constantinou CE, Hodges PW. A new method to quantify male pelvic floor displacement from 2D transperineal ultrasound images. Urology. 2013;81:685-9.

13. Kirschner-Hermanns R, Najjari L, Brehmer B, Blum R, Zeuch $\mathrm{V}$, Maass N, et al. Two- and three-/four dimensional perineal ultrasonography in men with urinary incontinence after radical prostatectomy. BJU Int. 2012;109:46-51.

14. Kumar A, Litt ER, Ballert KN, Nitti VW. Artificial urinary sphincter versus male sling for post-prostatectomy incontinence--what do patients choose? J Urol. 2009;181:1231-5.

15. Fischer MC, Huckabay C, Nitti VW. The male perineal sling: assessment and prediction of outcome. J Urol. 2007; 177:1414-8.
16. Sarlos D, Kuronen M, Schaer GN. How does tension-free vaginal tape correct stress incontinence? investigation by perineal ultrasound. Int Urogynecol J Pelvic Floor Dysfunct. 2003;14:395-8.

17. Armstrong SM, Miller JM, Benson K, Jain S, Panagopoulos K, DeLancey JO, et al. Revisiting reliability of quantified perineal ultrasound: Bland and Altman analysis of a new protocol for the rectangular coordinate method. Neurourol Urodyn. 2006;25:731-8.

18. Minardi D, Piloni V, Amadi A, El Asmar Z, Milanese G, Muzzonigro G. Correlation between urodynamics and perineal ultrasound in female patients with urinary incontinence. Neurourol Urodyn. 2007;26:176-82; discussion 183-4.

19. Dietz HP, Wilson PD. The 'iris effect': how two-dimensional and three-dimensional ultrasound can help us understand anti-incontinence procedures. Ultrasound Obstet Gynecol. 2004;23(3):267-71.

20. Chen R, Song $Y$, Jiang L, Hong X, Ye P. The assessment of voluntary pelvic floor muscle contraction by threedimensional transperineal ultrasonography. Arch Gynecol Obstet. 2011;284:931-6.

21. Castle EP, Andrews PE, Itano N, Novicki DE, Swanson SK, Ferrigni RG. The male sling for post-prostatectomy incontinence: mean followup of 18 months. J Urol. 2005;173:1657-60.

22. Giberti C, Gallo F, Schenone M, Cortese P. The bone-anchor sub-urethral sling for the treatment of iatrogenic male incontinence: subjective and objective assessment after 41 months of mean follow-up. World J Urol. 2008;26:173-8.

23. Onur R, Rajpurkar A, Singla A. New perineal bone-anchored male sling: lessons learned. Urology. 2004;64:58-61.

Correspondence address:

Danilo Souza Lima da Costa Cruz, MD Hospital Universitário Pedro Ernesto State University of Rio de Janeiro Av. 28 de Setembro, 77, 5th floor Vila Isabel, Rio de Janeiro, RJ, 20551-030, Brazil

Telephone: +55 21 2868-8122

E-mail: danilo.souzalima@hotmail.com 